\title{
Utilisation du foin et de l'ensilage du colza pour l'engraissement des agneaux
}

\author{
M Shamma, R Behjani, M Manssouri \\ Faculté Vétérinaire, BP 14155-6453, Tehran, Iran
}

Au cours d'essais précédents, nous avons constaté que l'appétibilité du colza vert est inférieure à celle des céréales immatures. Afin d'exploiter les excédents en fin d'hiver le colza peut être fané ou ensilé. L'objectif de cette étude a été de comparer l'utilisation, par des agneaux, de colza récolté à la même date, sous forme de foin et sous forme d'ensilage.

A la fin de l'hiver, une parcelle de colza au stade floraison a été récoltée pour moitié sous forme d'ensilage avec conservateur et pour moitié sous forme de foin séché au sol. L'essai a été conduit sur 2 groupes constitués chacun de 7 agneaux mâles sevrés et âgés de 3 mois, un groupe recevant l'ensilage, l'autre le foin. Le fourrage a été complémenté par de l'orge (MAT: $130 \mathrm{~g}$, UF:1) pour couvrir les besoins des animaux. L'essai a duré 100 jours au cours desquels les agneaux ont été pesés tous les 20 jours.

Les quantités de MS ingérées ont été légèrement plus élevées dans le groupe recevant le foin de colza $(+9,2 \%)$ mais, dans ce groupe, les apports azotés (ration totale) ont été inférieurs $(-32 \mathrm{~g} / \mathrm{j})$. Le gain de poids des agneaux recevant l'ensilage a été en moyenne de $16 \mathrm{~g} / \mathrm{j}$ plus élevé que celui des agneaux recevant le foin.

En conclusion, l'ensilage de colza donne de meilleurs résultats que le toin, tant pour les apports azotés que pour le gain de poids des animaux. Or, dans la plupart des régions d'Iran, le fanage du colza, plante la plus précoce de la fin de l'hiver, est très risqué. L'ensilage est une méthode de conservation plus coûteuse, mais qui permettra de mieux alimenter les animaux.

\begin{tabular}{lccccc} 
& \multicolumn{2}{c}{ MS ingérée $g / \mathrm{j}$} & \multicolumn{2}{c}{ MAT ingérées $\mathrm{g} / \mathrm{j}$} & \multicolumn{2}{c}{ gain $\mathrm{g} / \mathrm{j}$} \\
& Colza & Orge & Colza & Orge & \\
Ensilage & 689 & 356 & 117,5 & 43,6 & $174,1 \pm 47$ \\
Foin & 795,8 & 356 & 84,8 & 43,6 & $157,7 \pm 47$
\end{tabular}

